\title{
Transformação institucional e produção de conhecimento aplicado: a história do Ipea social
}

Márcia Pereira Cunha*

Resumo: Criado em 1964 para subsidiar a elaboração e execução de planos de desenvolvimento pelo governo, o Instituto de Pesquisa Econômica e Aplicada (Ipea) era, até meados dos anos de 1970, identificado principalmente com a área de política econômica. Atualmente, seus estudos abrangem políticas e públicos amplos e diversos. Por sua natureza de produtor de conhecimento aplicado, sua trajetória oferece ponto de vista profícuo para a leitura da história do país e das políticas nas áreas em que seus pesquisadores se dedicaram e vêm se dedicando. Com base em pesquisa documental, o presente artigo apresenta a evolução institucional do Ipea na área das políticas sociais. O objetivo é contribuir com a construção do instituto e de sua produção como objetos históricos e sociais que são, dimensão por vezes ofuscada por sua representação como ilha e excelência no âmbito da burocracia brasileira.

Palavras-chave: políticas sociais, Ipea, desenvolvimento, conhecimento aplicado, pobreza.

\section{Formação de recursos humanos para o desenvolvimento}

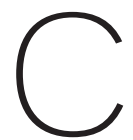

riado em 1964, há alguns fatos de referência obrigatória quando se trata da origem do Instituto de Pesquisa Econômica e Aplicada (Ipea). Sua primeira denominação foi Escritório de Pesquisa Econômica Aplicada (Epea), idealizado como órgão pensante do governo pelo ministro do Planejamento Roberto Campos, tendo recebido a revisão do Programa de Ação Econômica do Governo (Paeg) como primeira incumbência ${ }^{1}$. Até o ano de 1970, a instituição funcionou no Rio de Janeiro e sua vinculação com o Conselho Consultivo do Ministério do Planejamento do regime militar garantia-Ihe prestígio suficiente para que reunisse condições de produzir diagnósticos de abrangência setorial inédita já no início de suas atividades. Documento de 1965 (Ipea, 1965) registra a divisão dos trabalhos em 14 áreas, entre elas a de educação e de saúde pública e segurança

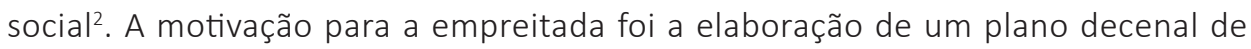
desenvolvimento que, após a saída de Roberto Campos do ministério, em 1967, acabou não implementado. Apesar disso, parte dos profissionais mobilizados para os diagnósticos de educação, saúde, demografia, habitação, previdência social e cultura foram reunidos na criação de um centro dedicado à face social do de-
Recebido: 02.12.16

Aprovado: 05.10.17

\begin{abstract}
* Doutora em sociologia pela Universidade de São Paulo (USP), São Paulo (SP), Brasil. <marcia.cunha@ gmail.com>.
\end{abstract}

1. Outros trabalhos já realizaram a reconstituição da criação do Ipea, parecendonos dispensável repeti-la. Loureiro (1997a; 1997b) e Nicolai Filho (2001) apresentaram versões narrativas; D’Araujo \& Castro (2004) e D'Araujo, Farias \& Hippolito (2004) apresentaram depoimentos; ou ainda trabalhos que tornam possive a proposição de interpretações alternativas sobre os períodos e episódios abordados, tal como na tese de doutorado (Cunha, 2012) em que este artigo se baseia. 0 mesmo esforço se repete aqui: o de trabalhar aspectos menos explorados do instituto, isto é, relacionados à produção de políticas sociais como educação, saúde, desigualdade social.

2. Além dessas duas, são elas: desenvolvimento econômico, política fiscal e monetária, 
desenvolvimento industrial, desenvolvimento agrícola, economia dos transportes, política e promoção de exportações, estatística econômica, planejamento urbano e habitação, planejamento regional, recursos minerais, turismo, programação de desenvolvimento econômico. Embora, considerando o objeto de nossa discussão, a área habitacional poderia destaca-se ao lado das áreas da educação e saúde pública e segurança social, não o fizemos pelo fato de que, na história do Ipea, não tenham sido centrais no núcleo que originou a produção social do instituto.

3. Decreto-Lei de 25 de fevereiro de 1967 . senvolvimento apregoado pela política de então: o Centro Nacional de Recursos Humanos (CNRH).

A noção de recursos humanos é representativa da perspectiva da instituição sobre os temas sociais do período. Em oposição ao precedente tom politizado dos anos Jango, passavam ao enquadramento das necessidades do desenvolvimento, ou do crescimento econômico com controle da inflação. O Paeg já indica essa compreensão. As políticas de "desenvolvimento social e valorização regional" (saúde, saneamento e previdência) e as que funcionavam como políticas-meio, nomeadas como de "produtividade social" (salarial, educacional, habitacional e agrária) tinham em comum o foco sobre o trabalhador e sua relação com o processo de desenvolvimento: como mão de obra a ser incorporada e, em momento posterior, como beneficiário do progresso. No caso do $\mathrm{CNRH}$, esse entendimento solidificou-se, de início, com base no tema da educação e da mão de obra, concepção inspirada no Projeto Regional Mediterrâneo da OCDE.

Desenvolvido no início da década de 1960, o objetivo do Projeto Mediterrâneo era planejar ações de educação e qualificação de mão de obra, segundo diagnóstico de necessidades estabelecidas para determinadas metas de desenvolvimento econômico. Foi implantado na Grécia, Itália, Portugal, Espanha, Turquia e lugoslávia e a reprodução dessa experiência em outros países era discutida em encontros e comissões com seus representantes (Hughes, 1993; Maddison, 2002; Hollister, 1967). Roberto Campos participava dessas discussões e seu provável interesse pela abordagem foi o que o levou a convidar o autor de um artigo sobre aquele projeto, Arlindo Lopes Corrêa, para comandar o setor de Educação e Mão de Obra do Epea. Foram os pesquisadores deste setor os responsáveis pela elaboração de seção de mesmo nome do Plano Decenal nunca implementado. Ao tomar corpo, o Epea passou, em 1967, a Fundação e teve o nome alterado para Instituto de Planejamento Econômico e Social ${ }^{3}$. É possível supor que a incorporação do termo "social" tenha origem nas negativas repercussões dos períodos recessivos de 1965 e 1966 que levaram à substituição de Castello Branco por Costa e Silva na Presidência da República. O setor de Educação e Mão de Obra segue o mesmo fortalecimento institucional, dando origem, em 1968, ao CNRH.

Ao falar do trabalho desenvolvido pelo centro, João Paulo dos Reis Velloso, considerado como primeiro dirigente da instituição, o caracteriza como filiado à teoria do capital humano (D’Araújo, Farias \& Hippolito, 2004: 24). Essa caracterização faz sentido na medida em que, na perspectiva desta teoria, a educação é vista como agregadora de valor econômico ao trabalhador. Também se justificaria por referências ao Projeto Mediterrâneo virem acompanhadas de menções a autores desta 
escola. Entretanto, alguns elementos contextuais permitem matizar esta definição e, assim, apreender com maior precisão a futura transformação da produção social do Ipea, nosso objeto aqui. A novidade da teoria, naqueles anos de 1960, sugere um movimento mais de aproximação do que propriamente sua total incorporação. Saída de grupos da Universidade de Chicago (Overtveldt, 2007), é razoável supor que sua implementação em ações concretas fosse adiada pelo encontro com as então assentadas diretrizes de ajuda para o desenvolvimento vindas de acadêmicos da Ivy League ${ }^{4}$, proeminentes no governo Kennedy (Dezalay \& Garth, 2002). As memórias de um reconhecido protagonista do Projeto Mediterrâneo vão nesse sentido, ao referir-se à atenção que o pioneiro trabalho de Theodore Schultz despertava nos economistas no início dos 1960 (Maddison, 2002: 243). Mais interessantes, no entanto, são os elementos que se referem à recepção da teoria do capital humano no próprio Ipea. Se nos Estados Unidos era o keynesianismo que amortecia a entrada em operação da produção de Chicago, no Brasil, o peso da Cepal entre economistas (profissão ainda em institucionalização) era inegável (Pécaut, 1989; Montecinos, 1996; Velloso, Tavares \& Chacel, 1997).

Em documento que tenta definir a estrutura organizacional e o funcionamento do centro (Ipea, 1970a: 1), discute-se a dificuldade de definição consistente da ideia de "recursos humanos" e, a seu lado, a de "capital humano" aparece, ainda, como seu sinônimo. O entendimento a respeito do que designa a expressão "recursos humanos" e a forma como essa compreensão define o campo de competência do centro estão determinados pela afirmação do caráter científico de sua apreensão e pela definição dos termos em que se dá sua instrumentalização.

Reconhecido [o também denominado "capital social"] em suas potencialidades em diversos níveis de interpretação, desde longa data, por sociólogos, antropólogos, educadores e outros especialistas carentes de instrumental metodológico de validade científica ortodoxa, só recentemente surgiram dados objetivos [...] indicadores do valor relativo dos Recursos Humanos entre as variáveis do desenvolvimento.

O mesmo contexto observado por economistas aparece sob a forma de vínculo da habilitação da força de trabalho de um determinado grupamento humano com seu ritmo e potencial de desenvolvimento. Por "habilitação" subentende-se, para a situação em pauta, as condições intelectuais e psicológicas, a capacidade científica e tecnológica e o estado de saúde e nutrição (Ipea, 1970a).
4. Designação do grupo de oito universidades norte americanas: Brown Columbia, Cornell, Dartmouth College, Harvard, Pensilvânia, Princeton e Yale.

Relatório de atividades do centro, referente ao primeiro semestre de 1969, reflete esse recorte, com a maior parte dos trabalhos realizados voltada para o que aparece 
sob o título de "programação de recursos humanos". A posterior abertura da instituição à teoria do capital humano realça, sob o olhar retrospectivo, o estágio ainda inicial - dos primeiros anos - de cultivo destas ideias entre seus pesquisadores. Neste momento, o CNRH tinha na superação do atraso e do subdesenvolvimento sua principal referência para o tratamento do tema da formação e qualificação de mão de obra. Atraso e subdesenvolvimento que, por sua vez, designavam e davam sentido ao que se entendia serem os problemas sociais.

\section{Concentração de renda e privilégio das especificidades dos problemas sociais}

A nomeação de João dos Reis Velloso para o Ministério do Planejamento do governo Médici, em outubro de 1969, deu impulso a um processo já iniciado no ano anterior, de transferência de setores do Ipea da cidade do Rio de Janeiro para Brasília, o que também atingiu o CNRH. Registros sugerem que este movimento não se tenha dado sem desconforto entre pesquisadores instalados na capital carioca, tendo-se mesmo cogitado a hipótese de que o CNRH lá se mantivesse, podendo autonomizar-se no futuro, tendo em vista o desenvolvimento que atingira (Ipea, 1970b; 1989). Divergências entre Velloso e o superintendente do $\mathrm{CNRH}$ resultaram no desligamento deste último, na transferência do centro para a capital do país e continuidade de sua expansão, já na nova casa.

A divisão entre as unidades do Rio de Janeiro e de Brasília é passagem especial da vida do Ipea. Por ser impossível tratar suas diferenças neste artigo, importa registrar os pontos que mais intimamente se relacionam com o recorte aqui definido. Embora a transferência da sede do Ipea do Rio para a capital federal só tenha sido

5. Decreto n.o 77.294, de 15 de março de 1976. formalizada em $1976^{5}$, a instituição já havia sido dividida em dois institutos, Instituto de Pesquisa (Inpes) e Instituto de Planejamento (Iplan) em 1970, criando um imaginário acerca de cada um facilmente captável em relatos de seus pesquisadores, seja para confirmá-lo, relativizá-lo ou negá-lo: o Inpes, no Rio de Janeiro, seria um instituto mais acadêmico, com objetivos definidos de forma mais distante das demandas diárias dos governos; o Iplan, ao contrário, privilegiaria o conhecimento aplicado, dedicando-se a desenvolver agenda mais afim às necessidades de planejamento e avaliação de políticas governamentais. Os pesquisadores dedicados aos temas sociais no Inpes preservaram, grosso modo, a linha tradicional de objetos e questões relacionados ao mundo do trabalho, como previdência, formação de mão de obra, educação. Os do CNRH seguiam a tendência de ampliação de temas e abordagens, acompanhando não só a expansão do Ipea - como referida há pouco -, mas a atuação do próprio governo federal na área. Nesta tendência, à produção sobre formação de mão de obra foram agregados trabalhos para subsídio de elaboração 
de programas e políticas na área de saúde e na de geração de emprego. Em 1974, o CNRH passa a ser formalmente dividido em três grupos: educação, trabalho e saúde. Também neste ano é lançado o II Plano Nacional de Desenvolvimento (II PND), representativo deste movimento.

A preocupação social do plano (Augusto, 1989; Draibe, 1994; Fagnani, 2005) tinha raízes em uma transformação do cenário de fins dos anos de 1960 e início dos de 1970 que, para a discussão dos problemas sociais, guarda acontecimento significativo: o debate sobre concentração de renda. A repercussão negativa da apresentação de um paper sobre a concentração de renda no Brasil (Veja, 1972), ocorrida ao longo da década de 1960 - em convenção da Associação Americana de Economia, pelo professor Albert Fishlow (1972) - foi episódio importante do que se começava a configurar como um debate a respeito do modelo de desenvolvimento brasileiro (Tolipan \& Tineli, 1975) ${ }^{6}$. Fishlow tinha passagem pelo Ipea e jovens pesquisadores que trabalharam com ele engrossaram o coro crítico, em oposição a outro então jovem pesquisador - Carlos Langoni - que, sob encomenda do ministro da Fazenda Delfim Netto, realizou estudo que não refutava os resultados encontrados por Fishlow, mas dava-Ihe interpretação diversa: o problema da concentração de renda resultava das diferenças de qualificação no campo da mão de obra brasileira (Langoni, 1973; 2005).

O embate entre Fishlow e Langoni reverberou sobre as produções do Ipea. No primeiro momento, envolveu diretamente os pesquisadores do Rio de Janeiro, que haviam trabalhado com Fishlow. Além desta filiação ao professor de Berkeley, tinham formação cepalina. Langoni, diferentemente, defendera sua tese em Chicago, em 19707 , baseada na teoria do capital humano que, como dito, àquela altura não encontrara recepção amistosa no Ipea (Castro, 1971; Malan, 1974; Malan \& Wells, 1973). A segunda onda de repercussão deu-se entre os pesquisadores do CNRH e a divergência foi igualmente explícita: a má formação dos trabalhadores era efeito e não causa de condições materiais precárias.

O cenário de contestação social que caracterizou o II PND como resposta estatal recebeu como apêndice este embate em torno da concentração de renda, estimulando pesquisadores do $\mathrm{CNRH}$ a buscarem o aperfeiçoamento da discussão sobre o social. A afirmação, no II PND, de que os problemas sociais exigiam respostas próprias, reflete o posicionamento destes profissionais. A criação de um Conselho de Desenvolvimento Social (a exemplo do que existia para a área econômica) para pensar e planejar especificamente políticas sociais e a estruturação de um sistema de informações e indicadores com o mesmo espírito são suas manifestações mais evidentes. O CNRH participa ativamente dessas ações, fornecendo informa-
6. Este debate se soma à discussão sobre o esgotamento do chamado "Milagre econômico", de 1968 a 1973.

7. Defendida em 1970, com o título A study in economic growth: the brazilian case e publicada pela primeira vez no Brasil, em 1973 (Langoni, 1973). 
ções, realizando estudos e pesquisas, subsidiando planos e programas. Essa atuação realimenta a renovação de sua produção, a mobilização para a construção de novo embasamento teórico para seus estudos. O aprimoramento conceitual dizia respeito à elaboração de uma noção de política social que escapasse a seu corrente entendimento como sinônimo de política setorial.

O núcleo desse novo conceito [de política social] consiste na caracterização dessa política não mais em função do setor de atividade ou área administrativa onde se formulam e executam as medidas de política, mas do beneficiário principal das ações propostas (Ipea, 1979: 1).

A primeira consequência dessa reformulação foi o tratamento das políticas setoriais como estratégias por meio das quais a política social cumpriria seu objetivo específico de "eliminar ou reduzir a 'pobreza crítica' e melhorar a distribuição de renda" (Ipea, 1979: 1). A segunda, extremamente relevante do ponto de vista institucional, foi o deslocamento e paulatino abandono da noção de recursos humanos. Disso resulta uma reorganização das relações entre as políticas: a de educação deixa de ser a "mais importante para o desenvolvimento", assim definida no sentido da avaliação de que "aplicações crescentes de recursos nessa área permitem maiores retornos que em outros setores" (Ipea, 1979: 2), tornando-se a política de emprego, como distribuidora de renda, o núcleo da política social. Para complementar a política de emprego, estariam outras políticas de atendimento às necessidades da população e, todas elas, em suas especificidades, deveriam contemplar medidas de priorização de "grupos mais pobres". A menção à pobreza e à sua redução, assim, aparece, nesse período, como foco de atenção constitutivo de todas as políticas setoriais (agora entendidas como ferramentas de intervenção numa área social mais amplamente delimitada e integrada) e como complementar no âmbito mais fundamental da geração de empregos.

\section{Politização dos problemas sociais}

Na medida em que se avança no tempo, a mobilização social tende a se intensificar e, com ela, a reformulação dos termos do debate acerca das condições de vida da população pauperizada. As crises econômica e do regime militar, na passagem para a década de 1980, incidiram de maneiras diversas sobre a sede carioca do Ipea e sobre o $\mathrm{CNRH}$. A crise da dívida e a crise energética tiveram o efeito de aproximar o Inpes dos centros decisórios de governo, envolvendo mesmo a substituição de pesquisadores da unidade por especialistas recrutados com o fim de apoiar especificamente a gestão destes problemas. Os pesquisadores do $\mathrm{CNRH}$, por sua vez, tive- 
ram importante participação na produção de conhecimento para a fundamentação de propostas de políticas progressistas no âmbito da redemocratização do país. Os temas mais tradicionais do centro - educação, trabalho e saúde - apareciam sob novas abordagens. À questão da geração de emprego, por exemplo, somava-se a análise das relações trabalhistas. A política de saúde aparecia circunstanciada pela reflexão acerca do acesso aos serviços na Nova República, a de educação relacionada às necessidades das populações de baixa renda. Além disso, o aparecimento de temas relativos à organização política, ao "espaço comunitário", à participação e a grupos específicos (como mulheres e crianças morando nas ruas) remete ao contexto de mobilização daqueles anos.

O tom politizado da discussão aparece também em trabalhos que relacionavam medidas ou ações governamentais à ideia de justiça social e à retomada do tema dos direitos. A intensificação dessa perspectiva fica evidente em relatório de atividades do CNRH de 1985, e baliza a definição e as propostas de condução das políticas sociais.

Propõe-se esforço de curto prazo para erradicação da pobreza absoluta, criando condições de expansão e ampliação da cobertura social pública, de modo a permitir o acesso universal, equânime e permanente aos benefícios do progresso e a plena realização dos direitos sociais da cidadania. A educação fundamental, a saúde pública, o saneamento básico, a habitação popular, a alimentação, a provisão adequada de segurança pública e de transporte coletivo urbano e o apoio ao pequeno agricultor associado ao processo de reforma e desenvolvimento agrário são bases desses direitos de cidadania (Ipea, 1985a: 2).

Ainda que com intensidades variantes, conforme as diferentes áreas setoriais, os pesquisadores do centro contribuíram para formulações posteriormente incorporadas à Constituição Federal de 1988. Os casos da educação e da saúde são exemplos dessa variação de intensidade. No caso da primeira, a forte presença do Partido da Frente Liberal no Ministério da Educação (Fagnani, 2005: 212ss.; Faria \& Castro, 1989) foi um obstáculo ao diálogo com atores externos e reduziu a colaboração com pesquisadores do Ipea, desde o início dos trabalhos da Assembleia Nacional Constituinte. Na saúde, diferentemente, a participação foi intensa e remonta aos estudos, às discussões e implementações de programas desde os anos de 1970, do Programa de Interiorização das Ações de Saúde e Saneamento, passando pelo Sistema Unificado e Descentralizado de Saúde, chegando, finalmente, ao Sistema Único de Saúde (Noronha \& Levcovitz, 1994). A coincidência deste momento com o de crise econômica, entretanto, encobre as muitas faces deste vigor. 
A narrativa institucional corrente descreve os anos de 1980 como período de declínio e perda de efetividade do Ipea: com o quadro muito bem formado, perdia profissionais para órgãos da gestão; com a crise econômica, perdia capacidade de remuneração compatível com a qualificação de seus técnicos; a própria função planejamento perdia sentido num contexto de urgências econômicas; a Esplanada já possuía quadros muito mais qualificados que na década anterior - quando a diferença com o Ipea era muito maior. O ano de 1987 condensa episódios que caracterizam esse período de transição. No âmbito geral, a insatisfação dos pesquisadores com a não implementação do Plano de Metas, elaborado em 1986, levou a que questionassem a encomenda do Programa de Ação Governamental para o período subsequente, 1987-1991. O endosso desta posição pelo superintendente do Iplan culminou em sua substituição, deixando claro o desgaste a que o instituto estava submetido. Pesquisadores recordam-se destes anos como de certa desilusão com as esperanças cultivadas no período de abertura do regime militar, em função da não renovação dos quadros políticos. Observavam, ainda, a incorporação imprópria do discurso e dos termos progressistas por grupos conservadores.

[...] tem-se avolumado a solicitação nesta área, muitas vezes por modismo típico dos dias atuais. Basta lembrar a inclusão de um segmento comunitário no Projeto Nordeste ou nos PDRIs do Acre e do Amazonas, bem como o tratamento de questões comunitárias no Minter [Ministério do Interior], de modo geral. Mas a colocação mais expressiva foi a criação da Seac [Secretaria de Ação Comunitária, criada no governo Sarney e alocada no Ministério do Planejamento], algo que, na verdade, escapou das mãos do Iplan (Ipea, 1985b: 2).

O Programa de Ação Governamental (1987-1991) confirma a análise presente nesta citação. Na educação, está mencionada a importância das escolas comunitárias; na habitação, a realização de mutirões comunitários; nas ações de assistência, o planejamento participativo. O público a ser atendido no "espaço da comunidade" é pulverizado: boias-frias, favelados, idosos, menores carentes, trabalhadores rurais carentes. Passagem importante, por outro lado, diz respeito às causas do agravamento das condições de pobreza: "a recessão do início dos anos 80" (Brasil, 1987: 261). Explicação que também vai se generalizar, sua importância está na dupla descontinuidade que estabelece. A primeira com o passado, por meio do abandono da noção de desenvolvimento como meio de resolução de problemas sociais, tanto no sentido da automática superação do atraso, quanto no de reformulação do modelo que havia levado à concentração da renda. A segunda descontinuidade se dá com a tematização predominante, naquele mesmo contexto, de enunciação dos problemas sociais como manifestações de injustiças sociais (Brant, 1980; Kowarick, 1994; 
Sader, 1988; Doimo, 1995). A recessão como causa dos problemas remetia à superação da crise como solução. Diferentemente das situações anteriores, o conteúdo do desenvolvimento e a perspectiva da injustiça social remetiam, de forma clara, a decisões e a escolhas políticas diante de diferentes interesses.

O Ipea, como um todo, e suas equipes, como não podia deixar de ser, não estavam imunes às turbulências do período. As indefinições e possibilidades abertas pelo momento de instabilidade política e econômica e a concomitante mobilização de setores da sociedade se traduzem na variedade de abordagens e questões levantadas pela produção social daqueles anos. Profusão acompanhada por paradoxal fragilidade institucional. As sucessivas alterações de estrutura representam, igualmente, esse momento. As justificativas para elas aparecem relacionadas a tentativas de reestruturar a equipe e a dinâmica de trabalho, de forma a recuperar a relevância perdida. No que se refere à área social, em 1986, o CNRH deixa de existir, sendo substituído por três coordenadorias: Educação e cultura; Saúde e previdência; Emprego e salário. Justificativa distinta é a de 1990, com a imposição de enxugamento das instituições públicas iniciada após a eleição de Fernando Collor. Já debilitada, a instituição responde aderindo ao discurso da busca por eficiência. A separação entre Inpes e Iplan deixa de existir, o instituto deixa de ser "de planejamento econômico e social" para se tornar "de pesquisa econômica" (denominação atual) e, na área social, reduz as três coordenadorias à Coordenação de Políticas Sociais. O esforço não impede que o Ipea entre na lista das instituições a serem fechadas, o que, por fim, não aconteceu. A enunciação dos problemas sociais como expressão de injustiças sociais e a afirmação de garantia de direitos como parâmetro para sua resolução pelo Estado, por sua vez, já tinham perdido força.

\section{As formas extremas, mensuráveis e localizáveis dos problemas sociais}

Concomitante à participação de pesquisadores das coordenações de políticas sociais nos debates para preparação da Constituição, era inaugurada, no Inpes, nova frente de trabalho: a construção de linhas de pobreza (Rocha, 1989). Claro que aqui os contornos gerais dos fatos acabam deixando em segundo plano pequenos, mas significativos, acontecimentos, como o de que entre os pesquisadores de Brasília também havia, desde meados dos anos de 1980, investimentos em novas técnicas e ferramentas para trabalho mais detalhado com as bases de dados então crescentemente disponíveis. Se quisermos, podemos retroceder até a década de 1970, quando, por determinação do Conselho de Desenvolvimento Social organizado a partir do II PND, pesquisadores do CNRH se engajaram na construção 
de um sistema nacional de indicadores sociais (Demo, 1976). A linha de pobreza construída no Inpes merece destaque em meio à evolução cotidiana das rotinas de pesquisa, em função do significado que assume no processo de transformação da produção social do Ipea. Desenvolvida em momento de ebulição e disputas entre entendimentos sobre o que seria a adequada oferta estatal de bens e serviços sociais, a linha de pobreza resultou de encomenda, pelo Banco Mundial, em dissonância com o ambiente interno, mas coerente com a atuação do demandante pelo mundo (Mosley, Harrigan \& Toye, 1991; Stahl, 1994; Haughton \& Khandker, 2009; Pereira, 2010). As relações entre os pesquisadores do CNRH e as missões do Banco Mundial desembarcadas em Brasília nos anos de 1980 são comumente descritas pelos primeiros em termos de negociação e resistência, ao passo que entre os do Rio de Janeiro predominam as noções de inspiração e colaboração. Assim, enquanto havia, entre pesquisadores do $\mathrm{CNRH}$, postura mais prevenida diante desta relação, entre os cariocas a adoção de instrumentos e concepções - compreendida como oportunidade de aprimoramento e atualização, independentemente de questões políticas - levou à acolhida do pedido.

A partir deste período, o emprego de técnicas para localização e mensuração de manifestações de problemas sociais se desenvolve. A não efetivação das pretendidas e demandadas garantias estatais de direitos sociais, bem como o desgaste deste tema em decorrência do abuso sofrido por sua incessante e inconsequente repetição, provavelmente abria espaço para novas abordagens e havia esta tendência em curso; tendência de que a linha de pobreza é apenas parte do problema. Se a segunda metade dos anos de 1980 foi de transição política e organizacional para o Ipea, o início da década seguinte abrigou transição nas formas de tratamento dos temas sociais. A produção do instituto ilumina duas faces desta transitoriedade. A primeira se mostra no uso de novas ferramentas e nova tipologia de informação que elas disponibilizam. A segunda, que se depreende deste uso, marca o caráter geracional da mudança institucional: pesquisadores com mais anos de casa tendem a empregar os novos recursos analíticos de forma mais contextualizada que os mais jovens, ou, tendem a analisar os dados obtidos a partir de leituras político-históricas que ocupam menos este último grupo. Coletânea publicada em 1993 e dedicada a temas sociais (com ênfase em índices, também novidade naquele período) é exemplo dessa transitoriedade e a comparação entre dois artigos - um sobre desigualdade de renda e outro sobre pobreza - ilustra essas sutis diferenças (Albuquerque, 1993).

No caso relacionado à desigualdade de renda (Albuquerque, 1993: 135), apesar da tradição de debate sobre o problema da concentração como decorrência do tipo de desenvolvimento implementado no Brasil, a questão não é tratada nesses termos. 
Diferentemente, a análise centra-se nas características dos atores e do mercado, estabelecendo graus diferenciados de influência de certas variáveis na configuração do fenômeno em discussão. A pobreza (Albuquerque, 1993: 189), por sua vez, é relacionada aos acontecimentos de determinado momento histórico - a década de 1980 -, concorde-se ou não com os fatores identificados como centrais. Outro ponto é a ausência de menção, no primeiro artigo, a políticas de geração de emprego - tendo-se em vista aquela tradição - como parte da intervenção em favor dos mais pobres, possibilidade apresentada no capítulo sobre pobreza. Finalmente, o capítulo sobre a desigualdade de renda - exceto pela menção ao "caráter imperioso" do objetivo de alteração de sua concentração, pela política de desenvolvimento (Albuquerque, 1993: 135) - concentra-se nas variações de resultados (a desigualdade entre rendas) obtidos pelas combinações diversas das variáveis que são seu ponto de partida e que compõem, também, sua conclusão, ou seja, as características dos indivíduos e das famílias na interação com as características do meio (neste caso, do mercado de trabalho e das políticas de estabilização).

É curiosa também a ressalva do organizador da publicação à noção de "humano" que acompanha a de "desenvolvimento", ao referir-se ao recém-lançado relatório do Programa das Nações Unidas para o Desenvolvimento (Pnud) e seu Índice de Desenvolvimento Humano (IDH) (UNDP, 1990). Seu argumento revela o ruído gerado pelo encontro entre o desenrolar de um raciocínio próprio e um ideário pronto, externo ao contexto, que é a referência do autor: depois de encadear ideias sobre evoluções históricas e sociais, relações entre indivíduos e coletivos, afirma que o homem "é o ator por excelência do desenvolvimento" e - ao considerar que o Pnud apresenta formulação semelhante - o adjetivo "humano" seria "dispensável" (Albuquerque, 1993: 12). A incorporação destas novas noções e formas de abordar os problemas sociais tende, como é usual num processo de sucessão entre ideias socialmente predominantes (Hall, 1989; Sikkink, 1991), a aparar arestas e a normalizar, massificar sua presença no discurso público, o que aconteceria na sequência.

Essa transição, apreendida na produção, se processava apesar dos riscos incorridos pelo Ipea na primeira metade da década de 1990, e não foi antes da substituição de Fernando Collor por Itamar Franco na Presidência da República que o instituto encontrou as condições para sua recuperação. Ao adotar estratégia de aproximação e abertura de interlocução com setores organizados da sociedade, Itamar Franco teve na Ação da Cidadania contra a Fome, a Miséria e pela Vida seu principal feito na área social. Para isso, utilizou-se de estudo em fase de desenvolvimento, no Ipea, por pesquisadores da Coordenação de Políticas Sociais de Brasília. $\mathrm{O}$ dado de 32 milhões de brasileiros estarem vivendo abaixo da linha da pobre- 
za foi extraído do Mapa da Fome (Peliano, 1993) e esteve na base tanto de ações públicas de estímulo à mobilização social, quanto de controvérsias a respeito da metodologia que o gerou. Este segundo caso diz respeito aos debates, no interior do Ipea, que opunham linhas metodológicas das unidades de Brasília e do Rio de Janeiro. Esta polêmica não se tornou pública e, no que diz respeito ao cenário externo, o Mapa da Fome marcou o que alguns autores apontaram como tendo sido a primeira vez que um problema social extremo como a fome havia sido colocado no centro da agenda de discussão pública (Draibe, 1993; Telles, 1998; Landim, 1998). A repercussão alcançada colocou o nome do Ipea em evidência, distinção que há muito não gozava, marcando também, desta forma, o primeiro passo para sua recuperação institucional. Garantia de recursos e realização de concursos deram início ao movimento de retomada de investimentos e atribuição de importância à instituição pelos governos federais que se sucederam, dos presidentes Itamar Franco e Fernando Henrique Cardoso.

O trabalho da Coordenação de Políticas Sociais, em Brasília, entrava no governo Fernando Henrique Cardoso fortalecido. Entretanto, as políticas desta gestão para a área social foram alvo de críticas e controvérsias. O debate "focalização versus universalização" das políticas sociais dá, em grande medida, o tom do embate então travado. Seu arrefecimento pode ser creditado à proeminência consolidada na passagem do primeiro para o segundo mandato do presidente Cardoso, e vencida por um dos lados da contenda: aquela mais afim à perspectiva da focalização. A nomeação do pesquisador Ricardo Paes de Barros à frente de grupo numeroso no Ipea-Rio para a coordenação da agora chamada Diretoria Social do Ipea, em 1999, coroa essa virada no interior da instituição.

Texto para discussão escrito neste ano (Barros, Mendonça \& Santos, 1999) ajuda a ilustrar algumas características dessa abordagem. Seu objetivo é o de

realizar uma análise descritiva aprofundada da estrutura da pobreza entre os idosos no Brasil em 1997, investigando a incidência e a natureza desta pobreza e o impacto que a presença e a renda dos idosos têm sobre a pobreza dos demais membros da sociedade (Barros, Mendonça \& Santos, 1999: 1).

O foco do trabalho detém-se sobre um grupo específico - os idosos - e a pobreza é compreendida como fenômeno igualmente delimitado, portador de natureza própria e descritível, cuja ocorrência é passível de previsão via cálculo. Assim como o idoso é definido por sua faixa etária, a pobreza é definida por linha de pobreza escolhida pelos autores. Idosos e pobreza serão confrontados nesse ambiente hipotético, com a inserção controlada de outras variáveis ou subcategorias, conforme o 
estudo requeira ou permita. As operações dos autores permitem-lhes, a cada passo, dar informações como as de que até os 60 anos, a renda de um indivíduo cresce para depois, declinar; que a desigualdade de renda é maior entre idosos que entre não idosos; ou que os não idosos sofrem mais "os efeitos da pobreza" (Barros, Mendonça \& Santos, 1999: 12) que os idosos. Cor, gênero e escolaridade também são testados sobre grupos de idosos e não idosos, de modo a que se chegue à conclusão de quais variáveis produzem maior ou menor incidência de pobreza sobre cada um deles. Os subgrupos recebem, ainda, mais subdivisões, que, por vezes, apresentam resultados distintos daqueles obtidos com as primeiras divisões. A reunião dessas informações compõe as conclusões do estudo, num retrato claro e exato do que seja a pobreza dos idosos.

Com ferramentas técnicas cada vez mais sofisticadas, nessa forma de pensar e falar sobre problemas sociais, o indivíduo é a unidade de análise privilegiada. Em lugar de menção a formas diversas de manifestação - como os anteriores objetos de políticas setoriais ou de direitos sociais -, a designação preferencial se dá por formulações mais sintéticas - como pobreza ou desigualdade, fome ou miséria - e o emprego de recursos para medição e cálculos econométricos permite que sejam tratadas como objetos quase palpáveis e de maneira localizada. A ineficiência das políticas tradicionais de enfrentamento dos problemas sociais justifica a adequação deste tipo de abordagem, segundo os seus defensores. A localização de grupos pobres em determinado contexto e a identificação de traços e características individuais que contribuem com maior ou menor intensidade para a condição de pobreza permitem a orientação de políticas para estes grupos e a intervenção sobre essas características, expediente garantidor de eficiência. No Ipea, pesquisadores empenhados nessa linha tendem a ver na teoria do capital humano e nos trabalhos de Langoni suas principais referências. Diferentemente do passado, em que essa teoria não encontrou terreno favorável para desenvolver-se, na virada do milênio, as condições para seu acolhimento se mostravam positivas.

O interesse em contrabalançar esta forma de tratamento dos problemas sociais, colocando em circulação termos e argumentos de viés menos focalizados como também representativos da produção social do Ipea, está na origem do boletim Políticas Sociais - Acompanhamento e Análise, idealizado e realizado por pesquisadores da equipe de Brasília, desde o ano 2000. Nesse caso, as referências continuam sendo aquelas afins à afirmação das políticas universais e a ideia de focalização significa a garantia de que os mais pobres tenham condições de usufruírem dessas mesmas políticas, em contraposição à otimização de recursos por área social, ineficiente por definição. Ainda que ferramentas e recursos possam ser comuns àqueles empregados pelos pesquisadores mais identificados com a abordagem 
8. Algumas referências publicadas no jornal Folha de S. Paulo, todas no caderno "Mercado": "Ipea muda foco de atuação, diz Pochmann" (17 Nov. 2007); "O expurgo no Ipea" (02 Dez. 2007); "Ipea suspende divulgação trimestral de previsões" (27 Jun. 2008); "Ipea faz concurso para dobrar pessoal e mudar perfil" (21 Set. 2008); "Concurso do Ipea faz ataque a neoliberalismo e globalização" (18 Dez. 2008); “O exame do Ipea reprova seu comissariado" (21 Dez. 2008) e, no caderno "Brasil": "O comissariado está destruindo o Ipea" (29 Jun. 2008). desenvolvida na unidade carioca, a contraposição foi construída na preservação da menção a um leque de políticas setoriais, cujo aperfeiçoamento deve ser compreendido como tarefa estatal de garantia dos direitos dos cidadãos. O contexto de críticas às reformas do Estado e identificação das políticas sociais do governo Fernando Henrique com condições impostas por organizações financeiras internacionais, no contexto do ajuste estrutural, acirraram a contraposição; mais ainda com a proximidade - agora se pode dizer, histórica - entre aquelas instituições e os pesquisadores da unidade do Rio de Janeiro.

A questão geracional também se intensifica, neste momento, em torno dos concursos para a seleção de novos profissionais. Após o esvaziamento dos anos de 1980 e 1990, as características do recrutamento significavam a definição das características do Ipea no futuro. A questão era: o perfil do novo técnico e, portanto, da instituição, deveria ser definido pelo aprofundamento da especialização matemática e sofisticação econométrica ou pelo fortalecimento de compreensão ampla a respeito da gestão pública em meio a cenários historicamente determinados por interesses políticos em constante conflito? Para os defensores da primeira posição, até aquele momento em posição privilegiada no interior da disputa, a crítica à ênfase em determinados conteúdos especializados - principalmente os matemáticos e estatísticos - era incompreensível, na medida em que se tratava de tipo de conhecimento de ponta e reconhecido internacionalmente, fator de elevada importância para essa visão. Mais que incompreensão, no entender desses pesquisadores, o investimento no recrutamento de profissionais com esse perfil compunha exatamente o conjunto de ações e iniciativas que ajudariam a recolocar o Ipea na linha de excelência de sua tradição. Para os defensores da segunda vertente, era o mesmo objetivo de recolocação do Ipea que levava à defesa de seleção de pesquisadores com domínio técnico, sem prejuízo de capacidade de leitura histórico-social. Embora tal disputa pudesse parecer apenas questão de ênfase em habilidades desejáveis por ambas perspectivas, as devidas compreensões dos significados acerca do domínio de tais competências ecoam leituras distintas da conjuntura em transição. Tratava-se de abordagem mais liberal, de um lado, e, de outro, de oposição a ela. Cisão cujas repercussões seguiram produzindo efeitos no interior da instituição - visíveis em acusações de aparelhamento do instituto, por um lado, e na defesa de uma guinada neodesenvolvimentista, por outro ${ }^{8}$ - e oferecendo elementos para apreensão ampliada de conflitos sociais atuais, fossem suas reverberações figuradas partidariamente ou pelos sentidos diversos atribuídos às políticas econômicas e sociais mais recentes. 


\section{Ipea, objeto social}

O Ipea é uma instituição estatal produtora de conhecimento, com missão de subsidiar a elaboração, implementação e execução de políticas públicas. Se considerarmos que todo objeto social ganha corpo em meio a relações e disputas entre agentes diversos e historicamente condicionados, a natureza do Ipea e as relações que estabelece (com outros órgãos do poder público, com instituições internacionais, com a academia) o tornam objeto privilegiado para a apreensão e análise da história do país e das áreas de intervenção pública a que seus pesquisadores se dedicaram. O reconhecimento social que define o Ipea como ilha de excelência na burocracia brasileira, entretanto, obscurece essa dimensão histórica do instituto, produzindo indesejada confusão entre tomá-lo como parte do cenário de eventos sociais e colocar em dúvida seu rigor, isenção ou qualidade. Esse equívoco é, ele mesmo, efeito dessa construção social: excelência como sinônimo de isolamento dos jogos e visões de mundo implicados nas escolhas de condução do país. Embora defensável pelos atores, no plano da experiência, tal isolamento é impossível sociologicamente. Este artigo pretendeu contribuir para a construção do Ipea como objeto de relevância sociológica e, mais especificamente, profícuo para os estudos da evolução da política social brasileira pós-1964.

A evolução institucional do Ipea esclarece como certas abordagens e formas de compreensão e tratamento de problemas sociais são construídos no tempo e nas relações, ainda que naturalizados aos olhos do presente. Assim, à periodização estabelecida pela própria instituição - de força, crise e recuperação institucionais -, propomos sobrepor outra, relacionada à evolução das formas de compreensão e das políticas dedicadas aos problemas sociais. No primeiro momento, a mão de obra para o desenvolvimento sintetizava a abordagem a informar a política social. Esse entendimento é predominante no início do regime militar e, consequentemente, nos anos iniciais do Ipea. Mantém-se válido até o início da década de 1980. No segundo momento, a partir da virada para os anos de 1990, a pobreza mensurada, localizada, esquadrinhada cumpre esse papel. É por essa via que o nome do Ipea ganha renovada notoriedade e que se dá sua recuperação institucional, mantendo sua produção relevante em diversas áreas da política pública até hoje. Os anos entre um e outro são literalmente anos de transição, mas - desta perspectiva - não de crise. Marcaram o declínio de uma concepção acerca dos problemas sociais, seguida da emergência de outra.

Os pesquisadores de Brasília avançavam na elaboração de uma concepção de política social não fragmentada e em consonância com o momento de mobilização por demandas baseadas em ideias de direitos, cidadania, igualitarismo. Depois de 
seu auge, na primeira parte da década de 1980, esse entendimento progressivamente perde força, ao passo que, na unidade do Rio de Janeiro, construíam-se as condições para emergência de outra abordagem, de maneira também paulatina. Os pesquisadores da unidade carioca aproximaram-se da agenda internacional que estimulava a produção dos recursos técnicos que, mais tarde, se disseminariam de forma vigorosa. O avanço técnico, na linha do que já mostrou Desrosières (2000), permitiu a construção de novas formas de representar problemas sociais (destacam-se os temas da fome, da pobreza, da miséria) e, com elas, novos discursos, ideias e proposições de formas de enfrentá-los.

Thelen (2003) defende que se olhe para a história, para apreender como instituições e/ou organizações se transformam ao longo do tempo, tema caro entre institucionalistas e para a sociologia das organizações (Powell \& DiMaggio, 1991; Dobbin, 1994; Fligstein, 1993). Mas o inverso também é verdadeiro: quando sociedade e instituições são considerados conjuntamente, os ganhos de compreensão mostram-se dos dois lados. A trajetória do Ipea - aqui, do Ipea social -, oferece rica perspectiva do campo das políticas e suas conformações sociais, valendo, ainda, para as mais recentemente implementadas. Esse objeto pouco explorado pode contribuir muito para a interpretação da gênese e das atuais configurações das intervenções públicas sobre os problemas sociais.

\section{Institutional change and applied knowledge: the history of social Ipea}

Abstract: The Applied Economic Research Institute (Ipea) was created in 1964 to support the design and implementation of government development plans. Until the mid-1970s, it was mainly identified with the area of economic policy. Currently, its studies cover large and diverse policies and public. By its nature of applied knowledge producer, its path offers fruitful point of view to grasp the history of the country and policy areas to which their researchers were dedicated. Based on documental research, this paper presents the institutional evolution of the Ipea, in the area of social policies. It aims to contribute to building the institute and its production as social and historical objects, a dimension sometimes overshadowed by its representation as island and excellence within the Brazilian bureaucracy.

Keywords: social policies, Ipea, development, applied knowledge, poverty.

\section{Referências}

ALBUQUERQUE, Roberto Cavalcanti (Coord.). O Brasil social: realidades, desafios, opções. Rio de Janeiro: Ipea, 1993. 
AUGUSTO, Maria Helena Oliva. Políticas públicas, políticas sociais e políticas de saúde: algumas questões para reflexão e debate. Tempo Social. Revista de Sociologia da USP, v. 1, n. 2, p. 105-119, 1989

BARROS, Ricardo Paes; MENDONÇA, Rosane; SANTOS, Daniel. Incidência e natureza da pobreza entre idosos no Brasil. Rio de Janeiro: Ipea, 1999.

BRANT, Vinicius Caldeira; SINGER, Paul (Orgs.). São Paulo: o povo em movimento. São Paulo: Vozes; Cebrap, 1980.

BRASIL. Plano de Ação Governamental, 1987.

CASTRO, Claudio de Moura e. Investimento em educação no Brasil: uma réplica. Revista Pesquisa e Planejamento Econômico, v. 1, n. 2, 1971. Disponível em: <http:// ppe.ipea.gov.br/index.php/ppe/issue/view/26>. Acesso em: 27 Abr. 2010.

CUNHA, Márcia P. Do planejamento à ação focalizada. Ipea e a produção de uma abordagem de tipo econômico da pobreza. Tese (Doutorado) - Universidade de São Paulo, São Paulo, 2012.

D'ARAUJO, Maria Celina; CASTRO, Celso. Tempos modernos: João Paulo dos Reis Velloso - memórias do desenvolvimento. Rio de Janeiro: FGV, 2004

D'ARAUJO, Maria Celina; FARIAS, Ignez Cordeiro de; HIPPOLITO, Lucia. Ipea 40 anos - apontando caminhos, 2004. Disponível em: <www.ipea.gov.br>. Acesso em: Jun. 2006.

DEMO, Pedro. Emergência do planejamento social no Brasil. Brasília: Ipea, 1976 (mimeo).

DESROSIÈRES, Alain. La politique des grands nombres - histoire de la raison statistique. Paris: La Découverte, 2000.

DEZALAY, Yves; GARTH, Bryant. The internationalization of Palace Wars - lawyers, economists, and the contest to transform Latin American States. Chicago: The University of Chicago Press, 2002.

DOBBIN, Frank. Forging industrial policy: the United States, Britain and France in the railway age. New York: Cambridge University Press, 1994.

DOIMO, Ana Maria. A vez e a voz do popular: movimentos sociais e participação política no Brasil pós-70. Rio de Janeiro: Relume-Dumará; Anpocs, 1995. 
DRAIBE, Sônia Miriam. As políticas sociais do regime militar brasileiro: 1964-1984. In: SOARES, G.; D'ARAUJO, M. C. (Orgs.). 21 anos de regime militar - balanços e perspectivas. Rio de Janeiro: Fundação Getúlio Vargas, 1994.

O redirecionamento das políticas sociais segundo a perspectiva neoliberal. As Políticas Sociais no Brasil - Caderno Técnico, n. 18, p. 21-39, 1993..

FAGNANI, Eduardo. Política social no Brasil (1964-2002): entre a cidadania e a caridade. Tese (Doutorado) - Universidade Estadual de Campinas(Unicamp), Campinas, 2005.

FARIA, Vilmar; CASTRO, Maria Helena Guimarães. Política social e consolidação democrática no Brasil . Caderno de Pesquisa do Nepp, n. 11. Campinas, Unicamp, 1989.

FISHLOW, Albert. Brazilian size distribution of income. The American Economic Review, v. 62, n. 2, p. 391-402, 1972.

FLIGSTEIN, Neil. The transformation of corporate control. Massachusetts: Harvard University Press, 1993.

HALL, Peter (Org.). The political power of economic ideas - keynesianism across nations. Princeton: Princeton University Press, 1989.

HAUGHTON, Jonathan; KHANDKER, Shahidur. Handbook on poverty + inequality. Washington: The World Bank, 2009.

HOLLISTER, Robinson. Technical evaluation of first stage of the Mediterranean Project. Paris: OECD, 1967.

HUGHES, Gerald. Projecting the occupational structure of employment in OECD countries. Paris: OECD, 1993.

INSTITUTO DE PESQUISA ECONÔMICA APLICADA (IPEA). Literatura econômica. Edição especial - 25 anos - A memória da produção do Ipea. Rio de Janeiro: Ipea, 1989.

— Relatório de atividades. Brasília: Ipea, 1985a (mimeo).

- Proposta de trabalho com respeito a política social participativa. Brasília: Ipea, 1985b (mimeo).

Síntese das atividades realizadas no período 1976-1979. Brasília: Ipea, 1979 (mimeo).

Consolidação do CNRH: preliminares sobre funções e estrutura organizacional. Brasília: Ipea, 1970a (mimeo). 
—. Nova estrutura para o IPEA (transitório). Brasília: Ipea, 1970b (mimeo).

_. Epea: History, organization, and functions. Brasília: Ipea, 1965 (mimeo).

KOWARICK, Lucio (Org.). As lutas sociais e a cidade - São Paulo passado e presente. Rio de Janeiro: Paz e Terra, 1994.

LANDIM, Leilah (Org.). Ações em sociedade - militância, caridade, assistência etc. Rio de Janeiro: NAU/Iser, 1998.

LANGONI, Carlos G. Distribuição da renda e desenvolvimento econômico do Brasil. Rio de Janeiro: Expressão e Cultura, 2005.

—_. As causas do crescimento econômico do Brasil. Rio de Janeiro: Apec, 1973.

- A study in economic growth: the Brazilian case. Tese (Doutorado) - University of Chicago, Chicago, 1970.

LOUREIRO, Maria Rita. Formação de quadros para o governo: as instituições de pesquisa econômica aplicada. In: LOUREIRO, M. R. (Org.). 50 anos de ciência econômica no Brasil (1946-1996) - pensamentos, instituições, depoimentos. Rio de Janeiro: Fipe; Vozes, 1997a.

- Os economistas no governo. Gestão econômica e democracia. Rio de Janeiro: Editora FGV, 1997b.

MADDISON, Angus. The origins and early years of the centre: a personal perspective. In: MACEDO, J. B.; FOY, C.; OMAN, C. P. (Eds.). Development is back. Paris: OECD Development Centre, 2002.

MALAN, Pedro. Ainda sobre a distribuição da renda. Revista de Administração de Empresas, v. 14, n. 2, 1974. Disponível em: <http://www16.fgv.br/rae/rae/index. cfm?FuseAction=EdicoesAnteriores $>$. Acesso em: 27 Abr. 2010.

MALAN, Pedro; WELLS, John. Distribuição da renda e desenvolvimento econômico do Brasil - resenha. Revista Pesquisa e Planejamento Econômico, v. 3, n. 4, 1973. Disponível em: <http://ppe.ipea.gov.br/index.php/ppe/issue/view/27>. Acesso em: 27 Abr. 2010.

MONTECINOS, Verónica. Economists in political and policy elites in Latin America. In. COATS, Alfred William. The Post-1945 internationalization of economics. Annual suplement to volume 28 History of political economy. Durham; London: Duke University Press, 1996. 
MOSLEY, Paul; HARRIGAN, Jane; TOYE, John. Aid and power - the World Bank \& policy-based lending, v. 1, "Analysis and policy proposals". London; New York: Routledge, 1991.

NICOLAI FILHO, Reinaldo. O Instituto de Pesquisa Econômica e Aplicada - Ipea (1964-1984). A institucionalização de uma burocracia. Dissertação (Mestrado) Universidade Federal do Rio de Janeiro, Rio de Janeiro, 2001.

NORONHA, José Carvalho; LEVCOVITZ, Eduado. AIS-SUDS-SUS: os caminhos do direito à saúde. In: GUIMARÃES, R.; TAVARES, R. Saúde e sociedade no Brasil: anos 80. Rio de Janeiro: Relume-Dumará, 1994.

OVERTVELDT, Johan Van. The Chicago School - How the University of Chicago assembled the thinkers who revolutionized the economics and business. Chicago: Agate; B2 Book, 2007.

PÉCAUT, Daniel. Os intelectuais e a política no Brasil - entre o povo e a nação. São Paulo: Ática, 1989.

PELIANO, Anna Maria T. M. (Coord.). O mapa da fome: subsídios à formulação de uma política de segurança alimentar. Brasília: Ipea, 1993.

PEREIRA, José Márcio Mendes. O Banco Mundial como ator político, intelectual e financeiro, 1944-2008. Rio de Janeiro: Civilização Brasileira, 2010.

POWELL, Walter; DI MAGGIO, Paul (Eds.). The new institutionalism in organizational analysis. Chicago: University of Chicago Press, 1991.

ROCHA, Sônia. Estabelecimento e comparação de Linhas de pobreza para o Brasil. Texto para Discussão n. 153. Rio de Janeiro: Ipea, 1989.

SADER, Eder. Quando novos personagens entraram em cena - experiências e lutas dos trabalhadores da Grande São Paulo, 1970-1980. Rio de Janeiro: Paz e Terra, 1988.

SIKKINK, Kathryn. Ideas and institutions - developmentalism in Brazil and Argentina. New York: Cornell University Press, 1991.

STAHL, Karin. Política social en América Latina. La privatización de la crisis. Nueva sociedad, n. 131, p. 48-71, 1994.

TELLES, Vera da Silva. A nova questão social brasileira. Estudos Marxistas, n. 6, p. 106-117, Praga, 1998. 
THELEN, Kathleen. How institutions evolve: insights from comparative historical research. In MAHONEY, J.; RUESCHEMEYER, D. (Eds.). Comparative historical analysis in the social sciences. New York: Cambridge University Press, 2003.

TOLIPAN, Ricardo; TINELLI, Arthur Carlos (Orgs.). A controvérsia sobre distribuição de renda. Rio de Janeiro: Zahar Editores, 1975.

UNITED NATIONS DEVELOPMENT PROGRAMME (UNDP). Human development report. New York; Oxford: Oxford University Press, 1990.

VEJA. A renda dos brasileiros. Veja, São Paulo, 1972. Disponível em: <http://veja. abril.com.br/arquivo_veja/capa_07061972.shtml>. Consulta em: 02 Fev. 2010.

VELOSO, João Paulo dos Reis; TAVARES, Maria da Conceição; CHACEL, Julian. Os institutos de pesquisa, o ensino de economia, a participação dos economistas no governo e outros temas. In: LOUREIRO, M. R. (Org.). 50 anos de ciência econômica no Brasil (1946-1996) - pensamentos, instituições, depoimentos. Rio de Janeiro: Fipe; Vozes, 1997. 
